\title{
CORRELAÇÃO ENTRE A PRODUTIVIDADE E OS RESULTADOS DE ANÁLISE FOLIAR E DE SOLO EM VINHEDOS DE NIAGARA ROSADA
}

\author{
Correlation between yield and results of leaf and soil analysis in Niagara Rosada vineyards
}

\author{
Marco Antonio Tecchio ${ }^{1}$, Erasmo José Paioli-Pires², Maurilo Monteiro Terra ${ }^{2}$, \\ Hélio Grassi Filho ${ }^{3}$, Juliano Corulli Corrêa ${ }^{4}$, Cássia Regina Yuriko Ide Vieira ${ }^{5}$
}

\begin{abstract}
RESUMO
Realizou-se nos municípios de Jundiaí e Louveira-SP um levantamento do estado nutricional e de produtividade de 20 vinhedos de 'Niagara Rosada' enxertada sobre o porta-enxerto IAC 766 e outros 20 enxertadas sobre o 'Ripária do Traviú'. Coletaram-se amostras de solo a 0-20 e 20-40 cm de profundidade na linha e na entrelinha de plantio e amostras de folha completa, limbo e pecíolo nas épocas de pleno florescimento e no início da maturação das bagas, visando correlacionar com os dados de produtividade. Verificou-se para o porta-enxerto IAC 766 correlações significativas entre a produtividade com os resultados das análises de solo e de folhas. A baixa produtividade verificada esteve relacionada ao excesso de nutrientes no solo, especialmente cálcio e magnésio, em função da calagem e adubação serem realizadas sem levarem em consideração a análise do solo. A produtividade correlacionou-se positivamente com os teores de potássio no solo, a relação $\mathrm{K} / \mathrm{Mg}$ nas folhas e os teores de potássio nas folhas; e negativamente com a relação $(\mathrm{Ca}+\mathrm{Mg}) / \mathrm{K}$ no solo e os teores de cálcio e magnésio nas folhas, exibindo o antagonismo entre o magnésio e o potássio.
\end{abstract}

Termos para indexação: Vitis, uva, porta-enxertos, análise foliar, análise de solo.

\begin{abstract}
An experiment was carried out at Jundiaí and Louveira-SP, to verify the relationships between nutritional and productivity aspects of the table grapevine cv. Niagara Rosada grafted on two different rootstocks: IAC 766 (20 vineyards) and 'Ripária do Traviú' (20 vineyards). Soil samples were collected at 0-20 and 20-40 cm depths within rows and inter-rows; samples of leaves, leaf blades and petioles were collected at full bloom and veraison, aiming to correlate them with productivity data. It was observed for the rootstock IAC 766 significant correlations between productivity and results of soil and leaf analysis. The low productivity verified was related to soil nutrients excess, mainly calcium and magnesium, due to the fact that liming and fertilization practices did not consider the soil analysis. The productivity was positively correlated with potassium amount in the soil, $\mathrm{K} / \mathrm{Mg}$ ratio and potassium contents in the leaves; and it was negatively correlated with $(\mathrm{Ca}+\mathrm{Mg}) / \mathrm{K}$ ratio in the soil, and calcium and magnesium leaf contents, showing an antagonism between magnesium and potassium.
\end{abstract}

Index terms: Vitis, grapevine, rootstock, leaf analysis, soil analysis.

(Recebido para publicação em 21 de dezembro de 2005 e aprovado em 31 de maio de 2006)

\section{INTRODUÇÃO}

O Estado de São Paulo é o maior produtor nacional de uvas para mesa, destacando-se a região leste com área de aproximadamente 7.870 ha. Nessa região destaca-se os municípios de Jundiaí, Vinhedo, Louveira, Indaiatuba, Valinhos, Itupeva e Campinas, com a produção de uva comum para mesa, representando $67 \%$ da área, predominando a cultivar Niagara Rosada, por apresentar características intrínsecas apreciadas pelo mercado consumidor (INSTITUTO DE ECONOMIA AGRÍCOLA, 2001).

Verificou-se que, embora a prática da adubação seja realizada pela maioria dos viticultores, eles a fazem de forma errônea, baseada em orientações empíricas, sem o conhecimento das reais condições do solo e das necessidades das plantas, utilizando os fertilizantes inadequadamente, ocasionando dessa maneira desequilíbrios nutricionais, o que acarreta queda na produção e na qualidade dos frutos. Dentre as inúmeras práticas culturais objetivando aumento em produtividade e na qualidade da uva, merece destaque a aplicação balanceada de nutrientes mediante adubações equilibradas, baseadas em análises químicas de solo e de folha. De acordo com Fráguas et al. (2002), Fráguas \& Silva (1998) e Terra et al. (1998), os vinhedos brasileiros poderiam alcançar elevadas produções com frutos de melhor qualidade caso fossem adubados adequadamente.

${ }^{1}$ Pesquisador Científico, Centro Avançado de Pesquisa Tecnológica do Agronegócio de Frutas - Instituto Agronômico de Campinas/IAC - 13214-820 Jundiaí, SP - tecchio@iac.sp.gov.br

${ }^{2}$ Pesquisador Científico, Instituto Agronômico de Campinas/IAC - Cx. P. 28 - 13001-970 - Campinas, SP - Bolsista do CNPq

${ }^{3}$ Professor Adjunto do Departamento de Recursos Naturais/Área Ciências do Solo da Faculdade de Ciências Agronômicas/UNESP.

${ }^{4}$ Pós-graduando do Departamento de Produção Vegetal da Faculdade de Ciências Agronômicas/UNESP - Cx. P. 237 - $18603-970$ - Botucatu , SP.

${ }^{5}$ Engenheiro Agrônoma, Dra, Pesquisadora - Idaterra/MS - Cx. P. 17 - 79803-040 - Dourados, MS. 
Sabe-se que, as alterações fisiológicas em função de desequilíbrios nutricionais, tornam-se mais evidentes nas folhas. Por essa razão, os diagnósticos nutricionais das plantas são feitos utilizando-se a folha, pela técnica denominada diagnose foliar. A diagnose foliar quando aliada aos resultados da análise de solo, torna-se muito útil para recomendação de adubação mais racional e equilibrada para os vinhedos e, portanto, mais econômica. Este princípio foi posto em prática inicialmente por Lagatu \& Maumé (1934), citados por Delmas (1971), que estudando variedades da espécie Vitis vinifera L., estabeleceram níveis de carência de nitrogênio baseados na diagnose foliar. Conradie \& Terblanche (1980) e Kenworthy (1961) enfatizaram que a avaliação do estado nutricional de videira obtida pela análise foliar tem sido considerada um dos métodos de diagnose mais seguro.

Uma das grandes utilidades da diagnose foliar consiste no levantamento nutricional das lavouras, trazendo relevante contribuição quando os resultados da análise foliar são acompanhados dos de produção (MALAVOLTA et al., 1997). O levantamento dos teores foliares em vinhedos de baixa produtividade, quando comparado com os de alta produtividade, tem a finalidade de identificar a existência de deficiências e excessos de nutrientes para direcionar a programação de pesquisas regionais de adubação.

Levantamentos nutricionais mediante análise de solo e de folhas visando identificar possíveis problemas nutricionais foram realizados por vários autores em diferentes regiões vitícolas (ALTEMIR, 2001; COSTA, 1998; DAL-BÓ et al., 1989; GERGOLETTI, 1995; GUILHERME, 1995; HIROCE et al., 1989; REGINA et al., 1998; SHARMA et al., 2003; TONIETTO 1994; YENER et al., 2002). Verificouse na maioria dos trabalhos correlações significativas entre a produtividade com os resultados das análises de solo e de folhas. Altemir (2001), Dal-Bó et al. (1989) e Sharma et al. (2003), constataram que a produtividade dos vinhedos correlacionou-se positivamente com o teor de potássio e com a relação $\mathrm{K} / \mathrm{Mg}$ nas amostras foliares, havendo uma correlação negativa com o teor de magnésio e correlação entre os teores de potássio no solo e no pecíolo.

Com base no exposto, sendo Jundiaí e Louveira importantes municípios produtores de Niagara Rosada e não havendo um diagnóstico nutricional realizado na região, o presente trabalho teve por finalidade fazer um levantamento da fertilidade dos solos, de folhas e da produtividade, em 40 vinhedos com videira 'Niagara Rosada', metade enxertada no porta-enxerto IAC 766 e outra no 'Ripária do Traviú'. Objetivou-se, dessa maneira, correlacionar os dados de produtividade com os resultados das análises de solo e de folhas e correlacionar os dados de análise de solo com os resultados das análises foliares.

\section{MATERIAL E MÉTODOS}

$\mathrm{O}$ experimento foi conduzido em vinhedos comerciais localizados nos municípios de Jundiaí e Louveira, SP, situados a $23^{\circ} 08^{\prime} \mathrm{S}$ e $46^{\circ} 55^{\prime} \mathrm{O}$, com altitude de $715 \mathrm{~m}$, apresentando médias anuais de $1.400 \mathrm{~mm}$ de precipitação pluviométrica, temperatura média de $19,5^{\circ} \mathrm{C}$ e umidade relativa do ar de 70,6\%. Na região há predomínio do solo Cambissolo Háplico Distrófico, segundo classificação da Embrapa (1999).

Para o levantamento do estado nutricional da videira 'Niagara Rosada', selecionou-se, em 19 propriedades particulares, 40 vinhedos conduzidos com bom nível tecnológico e que utilizavam práticas culturais semelhantes. As parreiras selecionadas estavam conduzidas no sistema de espaldeira, e podadas no sistema de cordão esporonado simples, sendo metade dos vinhedos enxertada sobre o portaenxerto 'Ripária do Traviú' e outra metade sobre o IAC 766.

A avaliação mais detalhada das áreas selecionadas foi realizada por um questionário, no qual foram registrados o espaçamento na linha, entrelinha de plantio e $\mathrm{n}^{\circ}$ de plantas vinhedo ${ }^{-1}$, para o cálculo da produtividade por hectare. Pelo questionário, verificou-se que poucos produtores realizavam análise de solo com freqüência. Quanto à análise foliar, todos os produtores nunca a realizaram. A adubação de manutenção, feita anualmente no período de março a maio, é realizada em sulcos no meio da entrelinha de plantio, em ruas alternadas, em $85 \%$ dos vinhedos pesquisados.

De cada vinhedo foram coletados, em julho de 2003, com o auxílio de um trado do tipo "sondaterra", vinte amostras simples de solo, nas profundidades de $0-20 \mathrm{~cm}$ e $20-40 \mathrm{~cm}$, de onde foram retiradas amostras de $0,5 \mathrm{~kg}$ para serem analisadas, as quais foram colocadas em sacos plásticos e enviadas ao Laboratório de Fertilidade do Solo do Departamento de Recursos Naturais - Área Ciência do Solo da Faculdade de Ciências Agronômicas UNESP Campus de Botucatu para análise química. Estas amostragens foram realizadas próximas à linha de plantio, distantes a $15 \mathrm{~cm}$ da planta, e no meio da entrelinha de plantio, obtendo-se quatro amostras compostas de solo em cada vinhedo. As quatro amostras de solo realizadas em cada vinhedo, foram submetidas à análise química de $\mathrm{pH}$ em $\mathrm{CaCl}_{2}$, matéria orgânica, $\mathrm{P}, \mathrm{K}, \mathrm{Ca}, \mathrm{Mg}, \mathrm{H}+\mathrm{Al}, \mathrm{SB}$, CTC e V\%, seguindo os métodos descritos por Raij et al. (2001) e os teores de B, Cu, Zn, Fe e Mn segundo a metodologia proposta por Camargo et al. (1986). 
As amostragens para a análise foliar foram realizadas em duas épocas do ciclo reprodutivo da videira: no pleno florescimento e no início da maturação das bagas, respectivamente, nos períodos entre 23/9 a 28/10/2003 e 19/11/2003 a 06/01/2004, em função das épocas de poda. Seguindo recomendações de Terra (2003), foram amostradas folhas completas e sadias, sendo a primeira folha recém madura do ápice para a base, que no início da maturação coincide com a oposta ao cacho. Para a amostragem de folhas foram selecionadas e marcadas, vinte e cinco plantas por vinhedo. Em cada época de amostragem coletou-se, nas plantas marcadas, seis folhas, sendo que três permaneceram inteiras e três foram separadas em limbo e pecíolo. Após as coletas nas duas épocas, as folhas, limbo e pecíolo, foram acondicionados separadamente em sacos de papel e enviadas ao laboratório. Realizou-se a análise química da folha, limbo e pecíolo no Laboratório de Nutrição Mineral de Plantas "Prof ${ }^{\mathrm{a}} \mathrm{Dr}^{\mathrm{a}}$ Leonia Aparecida de Lima" do Departamento de Recursos Naturais - Área de Ciência do Solo da Faculdade de Ciências Agronômicas UNESP/Campus de Botucatu, onde determinaram-se os teores de N, P, K, Ca, Mg, S, B, Cu, Fe, Mn, e Zn segundo metodologia descrita por Malavolta et al. (1997). Com base nos teores de $\mathrm{K}$ e $\mathrm{Mg}$, calculou-se a relação $\mathrm{K} / \mathrm{Mg}$. Dessa maneira obtiveram-se para cada vinhedo seis resultados de análises foliares.

Os dados de produtividade de cada vinhedo foram obtidos pelas informações criteriosas do produtor, sendo fornecido o número de caixas colhidas na área amostrada ou a produção por planta. Com base no peso das caixas, do número de caixas colhidas por área, número de plantas/área e espaçamento utilizado em cada vinhedo, calculou-se a produtividade por área em $\mathrm{t} \mathrm{ha}^{-1}$ e por planta em $\mathrm{kg}_{\text {planta }}{ }^{-1}$.

Os 40 vinhedos amostrados foram agrupados em função do porta-enxerto utilizado. Cada vinhedo representou uma repetição, totalizando 20 repetições por porta-enxerto, representado pelo IAC 766 e 'Ripária do Traviú'. Com os resultados das 20 repetições de cada portaenxerto, utilizando-se o programa SAS, calculou-se a estimativa dos coeficientes de correlação pelo método Pearson, descrito em Hoffmann \& Vieira (1998). Dessa maneira correlacionou-se: a produtividade com os resultados das análises de solo na linha e entrelinha de plantio nas profundidades de $0-20 \mathrm{~cm}$ e $20-40 \mathrm{~cm}$; a produtividade com os resultados das análises de folha completa, limbo e pecíolo coletadas no florescimento e no início da maturação das bagas e as correlações entre os resultados das análises de solo com os resultados das amostras de folhas.

\section{RESULTADOS E DISCUSSÃO}

Verificou-se que a produtividade da Niagara Rosada correlacionou-se com os resultados de análise de solo e de folhas apenas no porta-enxerto IAC 766, não havendo correlações com o porta-enxerto Ripária do Traviú.

A produtividade da 'Niagara Rosada' enxertada sobre o IAC 766 correlacionou-se positivamente com os teores de potássio no solo nas amostras realizadas na profundidade de $0-20 \mathrm{~cm}$ na linha e entrelinha de plantio (Figura 1) e negativamente com a relação $(\mathrm{Ca}+\mathrm{Mg}) / \mathrm{K}$ no solo, nas amostras realizadas na entrelinha a 0-20 e 20$40 \mathrm{~cm}$ de profundidade (Figura 2).

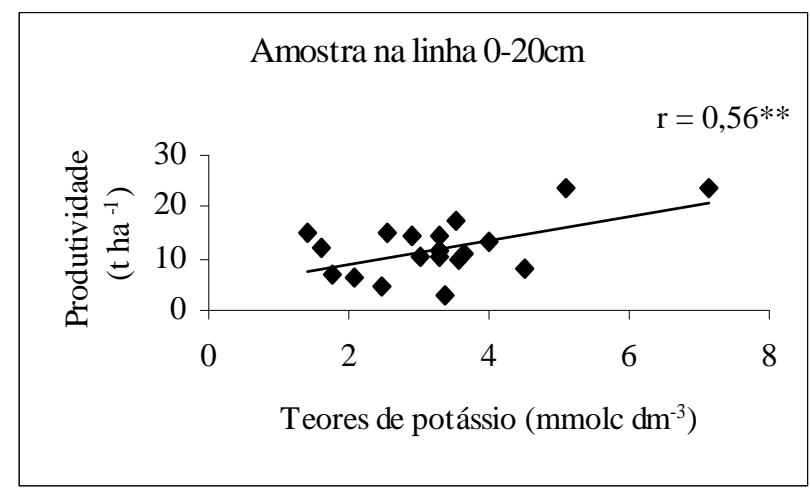

FIGURA 1 - Correlações entre a produtividade da 'Niagara Rosada' enxertada no IAC 766 com os teores de K no solo.

Ciênc. agrotec., Lavras, v. 30, n. 6, p. 1056-1064, nov./dez., 2006 

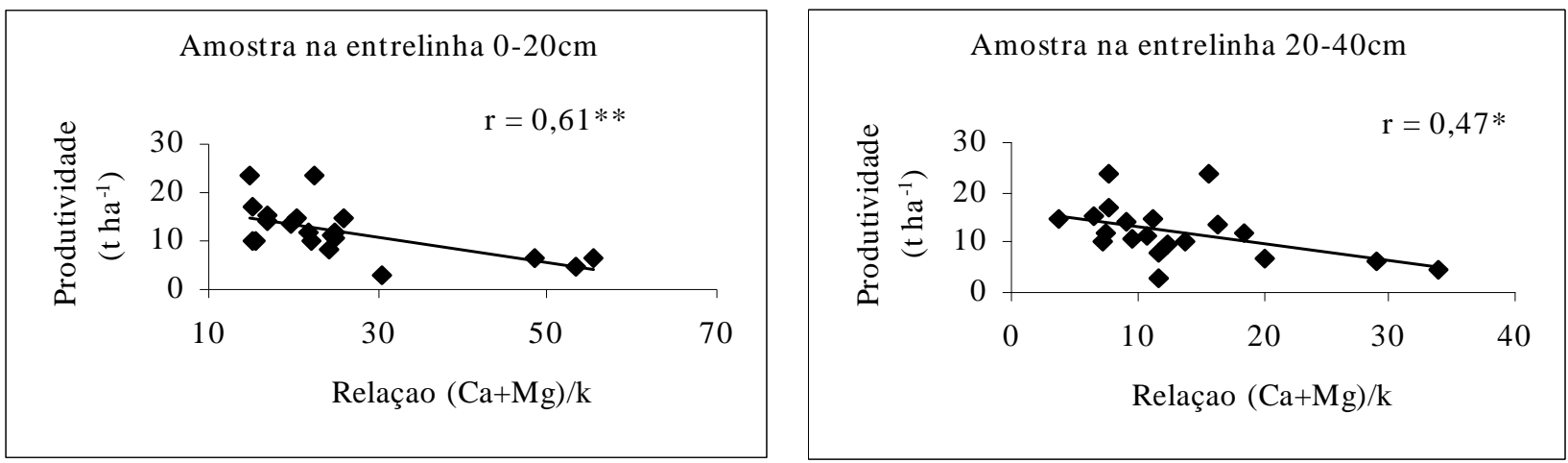

FIGURA 2-Correlações entre a produtividade da 'Niagara Rosada' enxertada no IAC 766 com a relação no solo de $(\mathrm{Ca}+\mathrm{Mg}) / \mathrm{K}$.

Verificou-se que altos teores de cálcio e magnésio no solo podem diminuir a absorção de potássio pelas plantas. Este antagonismo é mais evidente verificando as correlações entre os teores de cálcio, magnésio e potássio nas folhas com a produtividade. Os teores de cálcio e magnésio nas amostras de folha completa, limbo e pecíolo, coletadas durante o início da maturação das bagas correlacionaram-se negativamente com a produtividade. Para estes nutrientes, notou-se que a amostra da folha apresentou maiores coeficientes de correlação quando comparado com o limbo e pecíolo, sendo estas correlações mostradas na Figura 3.

Em relação ao potássio, observou-se uma correlação positiva entre a produtividade com os teores de potássio na amostra da folha completa, na coleta realizada durante o início da maturação das bagas (Figura 4). Estes dados condizem com as correlações obtidas com os resultados das análises de solo.

A influência dos teores foliares de magnésio e potássio sobre a produtividade também pôde ser observada pela relação entre $\mathrm{K} / \mathrm{Mg}$. Observa-se pela Figura 5, que a produtividade correlacionou-se positivamente com a relação $\mathrm{K} / \mathrm{Mg}$ nas amostras de folha completa e limbo, coletadas durante o início da maturação das bagas. Notouse que o coeficiente de correlação da relação $\mathrm{K} / \mathrm{Mg}$ na folha $(0,64)$ foi superior ao obtido com os teores de potássio $(0,42)$ e magnésio $(-0,60)$, concordando com Delas (1979) que considera mais adequada a relação entre potássio e magnésio do que os teores foliares desses nutrientes isolados para estabelecer um diagnóstico nutricional. Estes dados corroboram com os obtidos por Dal-Bó et al. (1989) que, em um levantamento nutricional de vinhedos no Vale do Rio do Peixe, também verificaram correlações positivas entre a produtividade com a relação $\mathrm{K} / \mathrm{Mg}$ e o teor de $\mathrm{K}$, e negativa com o teor de magnésio. Os autores também concluíram que a relação $\mathrm{K} / \mathrm{Mg}$ apresenta uma melhor correlação com a produtividade quando comparada com os teores isolados destes nutrientes.

Sharma et al. (2003) em levantamento nutricional realizado na Índia, também atribuíram a baixa produtividade em função de baixos teores de potássio nas folhas, seguido de altos teores de magnésio. A relação $\mathrm{K} / \mathrm{Mg}$ no pecíolo desses vinhedos também eram baixos. Para os demais nutrientes não houve correlação com a produtividade da 'Niagara Rosada's sobre o IAC 766.

Em relação às correlações entre os resultados das análises de solo com os teores de nutrientes na folha da 'Niagara Rosada' enxertada sobre os porta-enxertos IAC 766 e 'Ripária do Traviú', houve inúmeras correlações. No entanto, procurou-se mostrar somente aquelas relacionadas com os teores de cálcio, magnésio e potássio, tendo em vista que estes nutrientes e suas relações correlacionaram melhor com a produtividade, no caso do porta-enxerto IAC 766. Com os dois porta-enxertos, maiores teores de potássio no solo proporcionaram um aumento nos teores de potássio nas folhas, limbo e pecíolo. Verificaram-se maiores coeficientes de correlação na análise do pecíolo e da folha completa, sendo de 0,63 e 0,46, respectivamente para os porta-enxertos IAC 766 e para o 'Ripária do Traviứ (Figura 6).

Dal-Bó et al. (1989) em um levantamento nutricional de vinhedos no Vale do Rio do Peixe também obtiveram correlação positiva entre o potássio no solo com os teores de potássio no pecíolo coletado no início da maturação das bagas. Estes resultados concordam com os de Delas (1979) e Kenworthy (1961), os quais afirmaram que a análise do pecíolo é mais sensível para a avaliação dos teores de potássio na planta. 

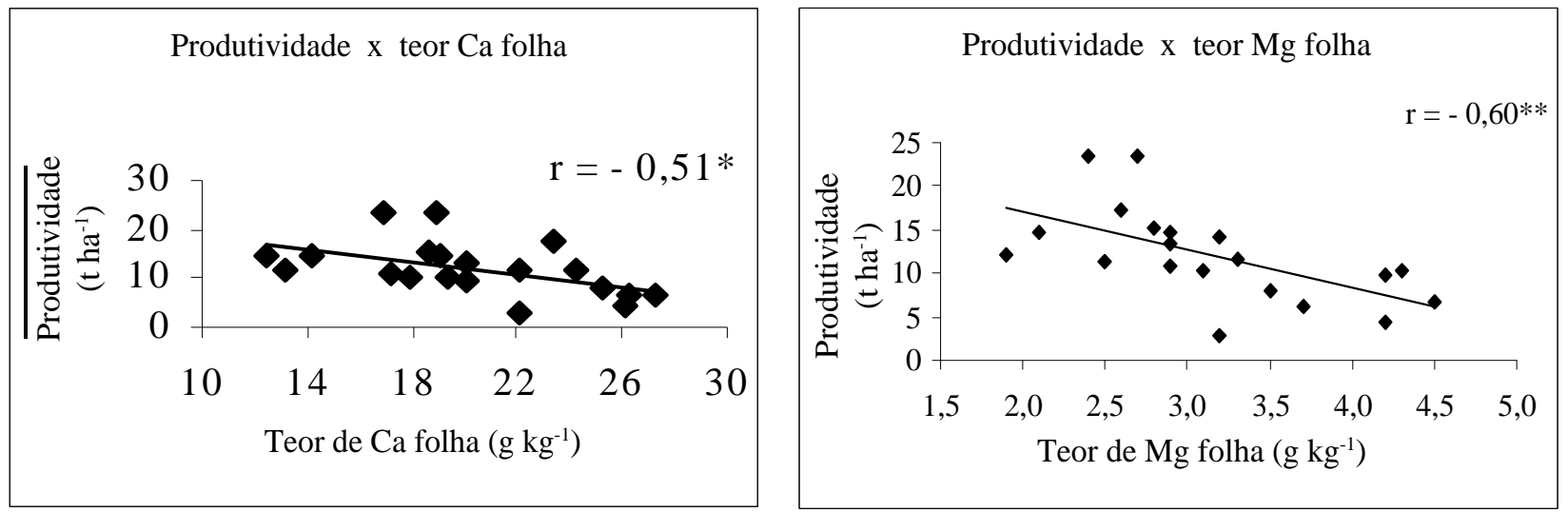

FIGURA 3 - Correlações entre a produtividade da 'Niagara Rosada' enxertada no IAC 766 com os teores de Ca e Mg na folha completa coletada durante o início da maturação das bagas.

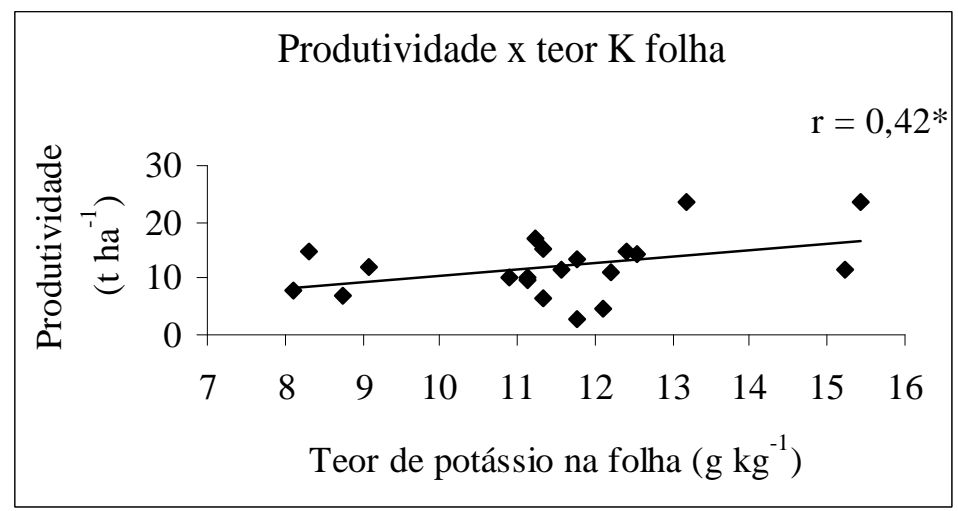

FIGURA 4 - Correlações entre a produtividade da 'Niagara Rosada' enxertada no IAC 766 com os teores de K na folha completa coletada durante o início da maturação das bagas.
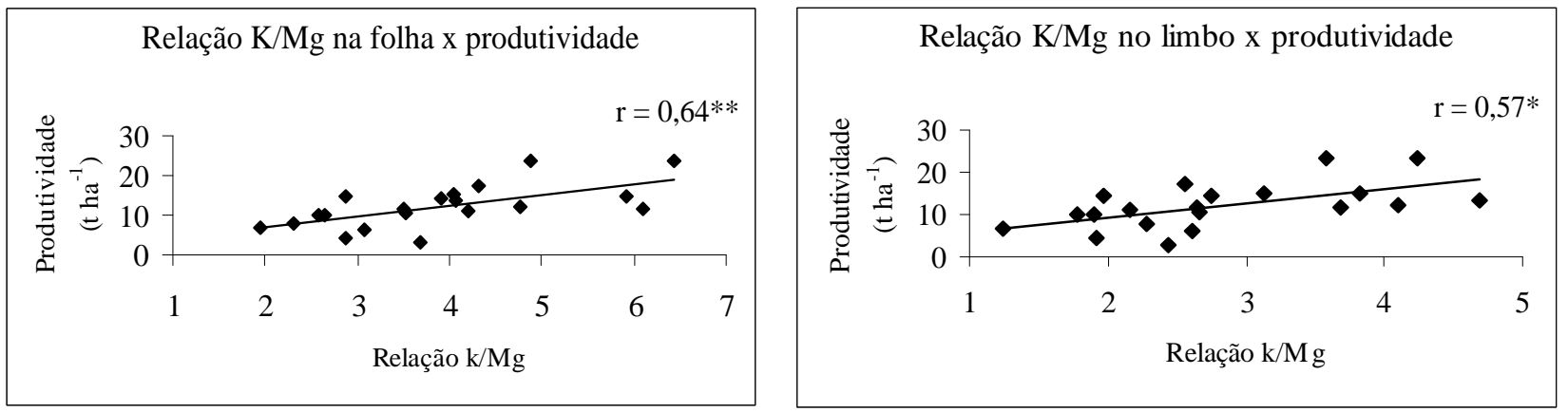

FIGURA 5 - Correlações entre produtividade da 'Niagara Rosada' enxertada no IAC 766 com a relação K/Mg na folha e no limbo coletados durante o início da maturação das bagas.

Ciênc. agrotec., Lavras, v. 30, n. 6, p. 1056-1064, nov./dez., 2006 

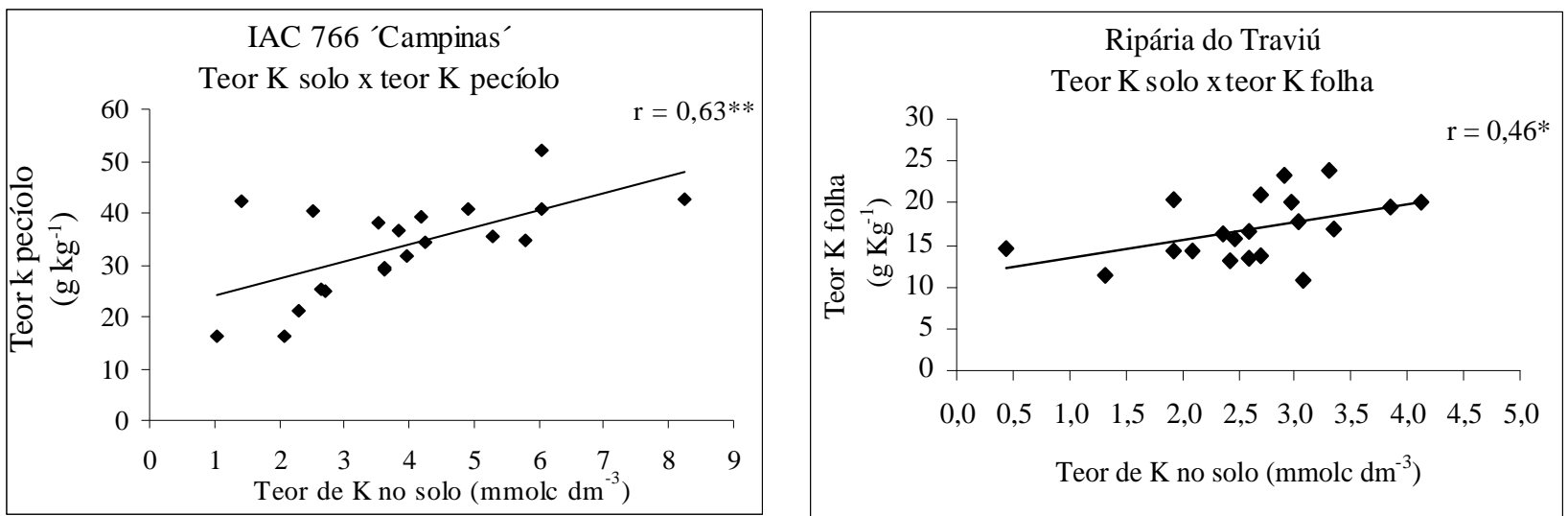

FIGURA 6 - Correlações entre o teor de K no solo e o teor de K nas análises foliares da videira 'Niagara Rosada' enxertada no IAC 766 e no 'Ripária do Traviú'.

Em relação ao cálcio, apenas com o porta-enxerto IAC 766 obteve-se um acréscimo nos teores foliares com o aumento deste nutriente no solo, sendo também a análise do pecíolo mais sensível para detectar esta correlação (Figura 7). Hiroce et al. (1989) também obtiveram correlações entre o teor de cálcio no solo e nas folhas, não havendo, no entanto, relações com a produtividade.

Quanto ao magnésio, os teores foliares foram positivamente correlacionados com os resultados das análises de solo. Verificou-se que o magnésio foi o único nutriente que apresentou teores na folha, limbo e pecíolo correlacionados com as amostras de solo realizadas na entrelinha e linha de plantio nas profundidades de 0-20 e $20-40 \mathrm{~cm}$. No entanto, a análise da folha completa e do pecíolo, respectivamente, nos porta-enxertos IAC $766 \mathrm{e}$ 'Ripária do Traviú', foram os que apresentaram maiores coeficientes de correlação (Figura 8). Yener et al. (2002) também obtiveram correlações positivas com os teores de potássio e magnésio no solo, com os teores nas amostras de folha, limbo e pecíolo.

Em relação ao potássio, verificou-se que os teores foliares correlacionaram-se negativamente com os teores de magnésio no solo, mostrando novamente a relação de antagonismo entre esses nutrientes. Verificou-se que, a amostra do limbo foliar no porta-enxerto IAC 766 e da folha completa no 'Ripária do Traviú' foram as que tiveram maiores correlações (Figura 9).

Ressalta-se que, além do estádio nutricional, inúmeros outros fatores podem afetar a produtividade da videira. As correlações aqui obtidas da produtividade com os resultados das análises de solo e de folha, embora não terem sido altas, podem ao menos indicar que houve alguma influência dos fatores nutricionais na produtividade.

Observou-se que a análise foliar apresentou sensibilidade em detectar as correlações entre os teores cálcio, magnésio e potássio no solo, bem como a interação eles. Mesmo no caso do porta-enxerto 'Ripária do Traviú', onde a produtividade não correlacionou-se com os dados de solo e de folhas, houve correlações entre estes nutrientes do solo e na planta. Sugere-se que para a 'Niagara Rosada' a análise foliar seja realizada no início da maturação das bagas, utilizando a folha ou o pecíolo, onde os dados correlacionaram-se melhor com a produtividade e com os resultados da análise do solo. Estes resultados corroboram com Hernando \& Mendiola (1965), os quais concluíram que a melhor época de amostragem é no início da maturação das bagas, onde há uma maior estabilidade nos teores de nutrientes nas folhas, permitindo maior amplitude da época de amostragem. A mesma conclusão foi fornecida por Fráguas et al. (2003).

Verificou-se também que as amostras de solo realizadas na entrelinha e linha de plantio a $0-20 \mathrm{~cm}$ de profundidade tiveram maiores correlações com a produtividade e com os resultados das análises foliares.

Conforme mencionado, anteriormente, poucos produtores das regiões em estudo realizam a análise de solo para auxiliar o programa de adubação. Este fato pode ter contribuído para o aparecimento de desequilíbrios nutricionais, principalmente no que diz respeito ao excesso de calagem no solo e o fornecimento inadequado de fertilizantes fosfatados e potássicos, ocasionando desta maneira um antagonismo da absorção de magnésio e potássio, conforme verificado neste trabalho. 


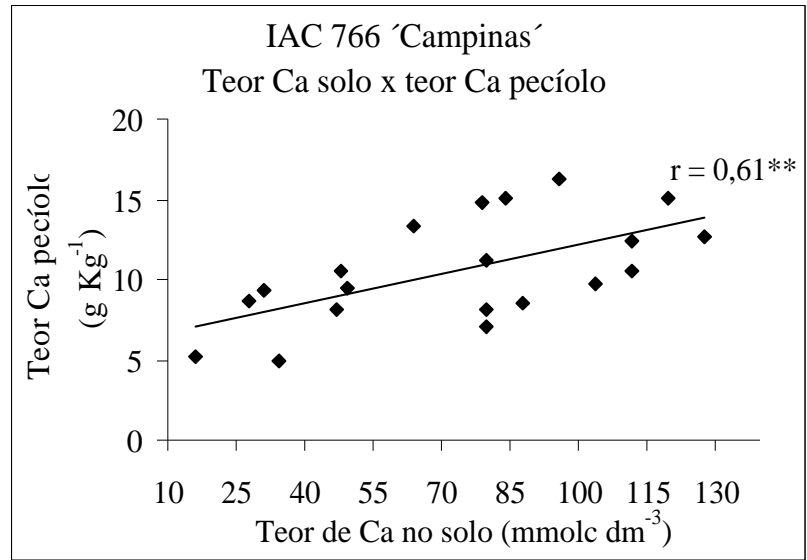

FIGURA 7 - Correlações entre o teor de Ca no solo e o teor de Ca no pecíolo da videira Niagara Rosada' enxertada no IAC 766.
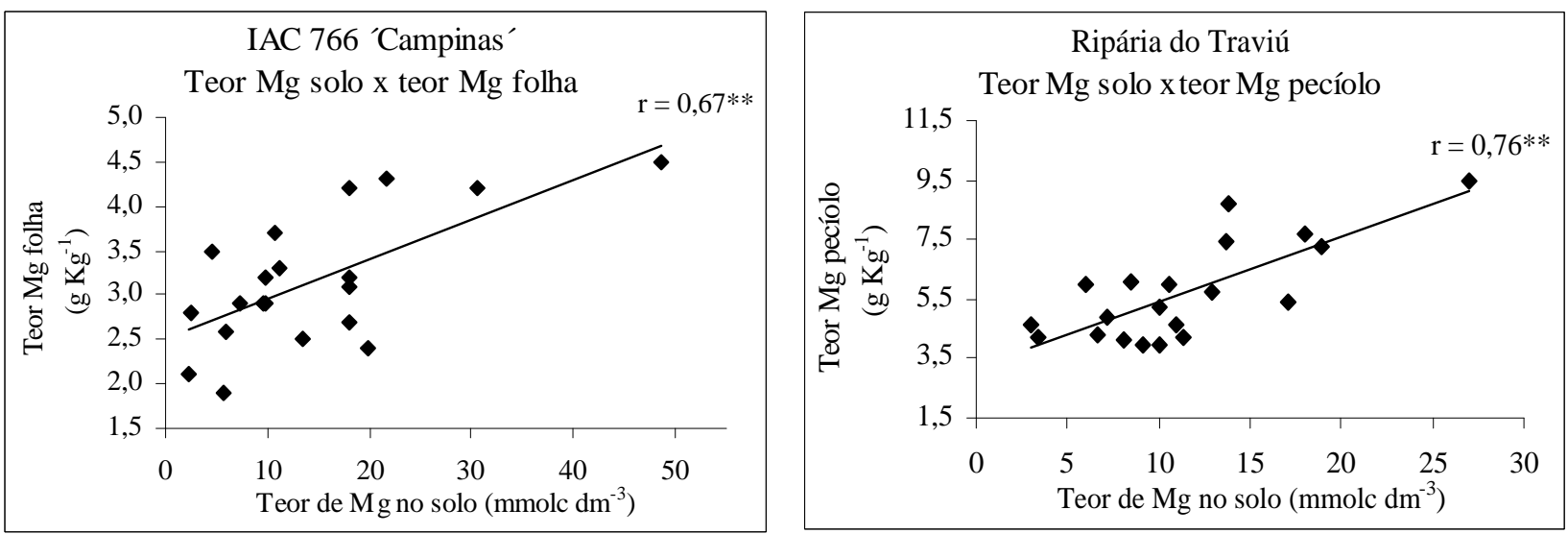

FIGURA 8 - Correlações entre o teor de magnésio no solo e o teor de magnésio nas análises foliares da videira Niagara Rosada' enxertada no IAC 766 e no 'Ripária do Traviú'.
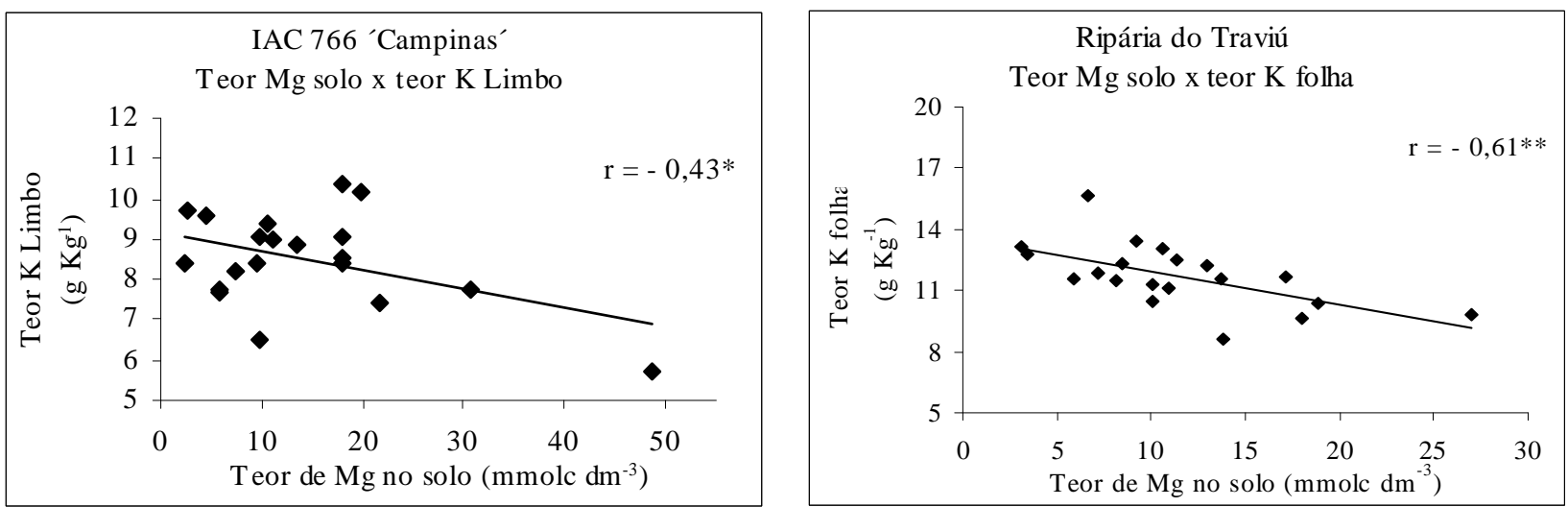

FIGURA 9 - Correlações entre o teor de Mg no solo e o teor de K nas análises foliares da videira 'Niagara Rosada' enxertada no IAC 766 e no 'Ripária do Traviú'.

Ciênc. agrotec., Lavras, v. 30, n. 6, p. 1056-1064, nov./dez., 2006 


\section{CONCLUSÕES}

A baixa produtividade verificada nos vinhedos está relacionada ao excesso de nutrientes no solo.

A amostragem de folhas realizada na época do início da maturação das bagas, bem como a amostragem de solo a $0-20 \mathrm{~cm}$ de profundidade, correlacionaram melhor com a produtividade.

A produtividade correlaciona-se positivamente com os teores de $\mathrm{K}$ e a relação $\mathrm{K} / \mathrm{Mg}$ ns folhas e negativamente com a relação $\mathrm{Ca}+\mathrm{Mg} / \mathrm{K}$ e os teores de $\mathrm{Ca}$ e $\mathrm{Mg}$ nas folhas.

\section{REFERÊNCIAS BIBLIOGRÁFICAS}

ALTEMIR, M. J. Caracterizacion del estado nutritivo de la variedad Moristel em la denominacion de origem Somontano. Georgica, [S.1.], n. 8, p. 61-73, 2001.

CAMARGO, F. A. O.; MUNIZ, A. C.; JORGE, J. A.; VALADARES, J. M. A. S. Métodos de análise química, mineralógica e física do solo do Instituto Agronômico de Campinas. Boletim Técnico Instituto Agronômico, Campinas, n. 106, 1986.

CONRADIE, W. J.; TERBLANCHE, J. H. Leaf analysis of deciduous fruit trees and grapevines summer rainfall area. Pretoria: Department of Agricultural Technical Services, 1980. 2 p. (Table grapes: Summer Rainfall, G. 4).

COSTA, F. Avaliação do estado nutricional da videiro cultivar Itália em três estádios de desenvolvimento, na região de Jundiaí-SP, utilizando o método DRIS. 1998. 91 f. Dissertação (Mestrado em Agronomia/Fitotecnia) Escola Superior de Agricultura "Luiz de Queiroz", Universidade de São Paulo, Piracicaba, 1998.

DAL-BÓ, M. A.; BECKER, M.; BASSO, C.; STUKER, H. Levantamento do estado nutricional da videira em Santa Catarina por análise de solo e tecido. Revista Brasileira de Ciência do Solo, Campinas, v. 13, p. 335-340, 1989.

DELAS, J. Place de I'analyse foliaire dans I'elaboration du conseil de fumure em viticulture. In: COLLOQUE SUR DIAGNOSTIC FOLIARE, 1979, Champenoux. Resumes... Champenoux: [s.n.], 1979. p. 107-116.

DELMAS, J. Recherches sur la nutrition minérale de la vigne, Vitis vinifera var. Merlot, en aquiculture. Bordeaux: Universidade de Bordeaux, 1971. $266 \mathrm{p}$.
EMPRESA BRASILEIRA DE PSQUISA AGROPECUÁRIA. Sistema brasileiro de classificação do solo. Brasília, DF; Rio de Janeiro, 1999. 42 p.

FRÁGUAS, J. C.; SILVA, D. J. Nutrição e adubação da videira em regiões tropicais. Informe Agropecuário, Belo Horizonte, v. 19, n. 194, p. 70-75, 1998.

FRÁGUAS, J. C.; REGINA, M. A.; ALVARENGA, A. A.; ABRAHÃO, E.; ANTUNES, L. E. C.; FADINI, M. A. M. Calagem e adubação para videira e fruteiras de clima temperado. Belo Horizonte: Epamig, 2002. 44 p. (Boletim técnico, 65).

FRÁGUAS, J. C.; MIELE, A.; SILVA, E. B. Grapevine nutritional diagnose methods for the 'Serra Gaúcha'viticultural region, Brazil. Journal International des Sciences de la Vigne et du Vin, Bordeaux, v. 37, n. 1, p. 15-21, 2003.

GERGOLETTI, I. F. Avaliação do estado nutricional da videiro cultivar Itália em três estádios de desenvolvimento em São Miguel Arcanjo,SP, utilizando o método DRIS. 1995. 84 f. Tese (Doutorado em Agronomia/Solos e Nutrição de Plantas) - Escola Superior de Agricultura "Luiz de Queiroz”, Universidade de São Paulo, Piracicaba, 1995.

GUILHERME, M. A. S. Avaliação do estado nutricional da videira 'Itália', em três estádios de desenvolvimento, na região de Jales-SP, utilizando o método DRIS. 1995. $81 \mathrm{f}$. Dissertação (Mestrado em Agronomia/Solos e Nutrição de Plantas) - Escola Superior de Agricultura "Luiz de Queiroz”, Universidade de São Paulo, Piracicaba, 1995.

HERNANDO, V.; MENDIOLA, J. Yields in a acordance with foliar analysis of vineyards in two different areas (La mancha and la rioja). In: COLLOQUIUM EUROPEAN CONTRÔLE NUTRITION MINERALE FERTILITY VITICULTURE ARBORICULTURE, 1., 1964, Montpellier. Resumos... Montpellier: Farnham Royal, 1965. p. 507.

HIROCE, R.; TERRA, M. M.; GREGORI, P. T. Levantamento nutricional de videiras de Itupeva, Região de Jundiaí, SP. In: CONGRESSO BRASILEIRO DE FRUTICULTURA, 10., 1989, Fortaleza. Anais... Fortaleza: Sociedade Brasileira de Fruticultura, 1989. p. 480-486.

HOFFMANN, R.; VIEIRA, S. Análise de regressão: uma introdução à econometria. São Paulo: Hucitec, 1998. 379 p. 
INSTITUTO DE ECONOMIA AGRÍCOLA. Produção e número de plantas de videira no Estado de São Paulo: dezembro de 2000. Disponível em: <http:// Wwww.iea.sp.gov.brì' Acesso em: 12 set. 2001.

KENWORTHY, A. L. Interpreting the balance of nutrient elements in leaves of fruit trees. In: Plant analysis and fertilizers problems. Esat Leasing: [s.n.], 1961. p. 2843.

MALAVOLTA, E.; VITTI, G. C.; OLIVEIRA, S. A. Avaliação do estado nutricional de plantas: princípios e aplicações. 2. ed. Piracicaba: Potafos, 1997. 319 p.

RAIJ, B. van; ANDRADE, J. C.; CANTARELLA, H.; QUAGGIO, J. A. Análise química para avaliação da fertilidade de solos tropicais. Campinas, Instituto Agronômico, 2001. 285 p.

REGINA, M. A.; ALVARENGA, A. A.; CHALFUN, N. J.; CHALFUN JÚNIOR, A. Levantamento nutricional e diagnóstico agronômico dos vinhedos de caldas. Revista Brasileira de Fruticultura, Cruz das Almas, v. 20, n. 1, p. 15-20, 1998.

SHARMA, J.; SHIKHAMANY, S. D.; SINGH, R. K. Studies on inward leaf curl disorder in grape. Indian Journal of Horticulture, [S.1.], v. 60, n. 3, p. 236-238, 2003.
TERRA, M. M.; POMMER, C. V.; PIRES, E. J. P.; PASSOS, I. R. S.; MARTINS, F. P.; PETTINELLI, A. J. R.; RIBEIRO, I. F. A. Comportamento de porta-enxertos para o cultivar de uva de mesa Niagara Rosada em Jundiaí, SP. In: CONGRESSO BRASILEIRO DE FRUTICULTURA, 9., 1987, Campinas. Anais... Campinas: Sociedade Brasileira de Fruticultura, 1988. p. 721-725.

TERRA, M. M. Nutrição, calagem e adubação. In: POMMER, C. V. Uva: tecnologia de produção, pós-colheita, mercado. Porto Alegre: Cinco Continentes, 2003. cap. 7, p. 405-476.

TERRA, M. M. et al. Principais cultivares de mesa. In: Tecnologia para produção de uva Itália na região noroeste do Estado de São Paulo. Campinas: Coordenadoria de Assistência Técnica Integral/Centro de Comunicação Rural, 1998. 81 p. (Documento técnico, 97).

TONIETTO, J. Diagnóstico nutricional das videiras Isabel e Concord através da análise foliar.

Revista Brasileira de Fruticultura, Cruz das Almas, v. 16, n. 1, p. 185-194, 1994.

YENER, H.; AYDIN, S.; GULEC, I. Nutrients status of Kavaklidere vineyards in Alasehir Province. Anadolu, [S.l.], v. 12, n. 2, p. 110-138, 2002. 